\title{
Urgences
}

\section{Liminaire 2 (sortie)}

\section{André Gervais et Renald Bérubé}

Numéro 15, octobre 1986

Épigraphiques

URI : https://id.erudit.org/iderudit/025359ar

DOI : https://doi.org/10.7202/025359ar

Aller au sommaire du numéro

Éditeur(s)

Urgences

ISSN

0226-9554 (imprimé)

1927-3924 (numérique)

Découvrir la revue

Citer ce document

Gervais, A. \& Bérubé, R. (1986). Liminaire 2 (sortie). Urgences, (15), 103-103.

https://doi.org/10.7202/025359ar

Ce document est protégé par la loi sur le droit d'auteur. L’utilisation des services d'Érudit (y compris la reproduction) est assujettie à sa politique d'utilisation que vous pouvez consulter en ligne.

https://apropos.erudit.org/fr/usagers/politique-dutilisation/
Cet article est diffusé et préservé par Érudit.

Érudit est un consortium interuniversitaire sans but lucratif composé de l’Université de Montréal, l'Université Laval et l'Université du Québec à Montréal. Il a pour mission la promotion et la valorisation de la recherche. https://www.erudit.org/fr/ 


\section{Liminaire 2 (sortie)}

Exergue. n.m. (1636; lat. mod. exergum "espace hors d'oeuvre", gr. ergon "oeuvre"). [...] 2 Fig. Ce qui présente, explique. Mettre un proverbe en exergue à un tableau, à un texte. V. Epigraphe.

Petit Robert I

On aura compris, à la lecture de cette épigraphe - et, espéronsle, de ce numéro - , que nous ayons choisi sans hésitation, et pour deux raisons, le terme d" "épigraphe".

D'exergue à épigraphe, n'y a-t-il pas ce V. — "V: voyez deux points" dit Jacques Rigaut (Ecrits) - qui renvoie clairement à celui des deux qui est le terme de référence.

Mais nous préférons l'autre raison: en "générant" ainsi un texte, l'épigraphe ne peut plus être [dans] un "espace hors d'oeuvre".

On doit aux travaux de Jean Ricardou, particulièrement, de considérer comme éléments constitutifs, intégrés, éléments organiques, producteurs d'un texte - un texte qui, par ailleurs, va de l'incipit à l'explicit - la page de couverture, la dédicace, l'épigraphe, entre autres.

A.G. / R.B. 